\title{
Natural Enemies of Rugose Spiraling Whitefly, Aleurodicus rugioperculatus Martin (Insecta: Hemiptera: Aleyrodidae) in the South Florida Landscape ${ }^{1}$
}

\author{
Siavash Taravati, Catharine Mannion, Holly Glenn, and Lance Osborne ${ }^{2}$
}

\section{Introduction}

Rugose spiraling whitefly, Aleurodicus rugioperculatus Martin, is a member of the subfamily Aleurodicinae, originally described from Belize in 2004 on coconut, Cocos nucifera (Martin 2004). This species was first observed in south Florida in 2009, which was the first report of its occurrence in the United States. As of July 2013, it has been found in 17 counties in south and central Florida. This whitefly has been reported on more than 60 plant species, which include gumbo limbo (Bursera simaruba), coconut (Cocos nucifera), black olive (Bucida buceras), avocado (Persea americana), Calophyllum spp., and giant white bird of paradise (Strelitzia nicolai). There is little information on the biology and management of this species in the literature (Stocks and Hodges 2012). In this publication, we will describe the predators and parasitoids found feeding on this whitefly in the south Florida landscape.

\section{Encarsia guadeloupae Viggiani (Hymenoptera: Aphelinidae)}

This solitary parasitoid belongs to the family Aphilinidae and has been reported from Aleurodicus cocois (Curtis), Aleurodicus dispersus Russell, Aleurodicus dugesii Cockerell, Aleurodicus floccissimus (Martin, Hernandez-Suarez, and Carnero), Aleurodicus maritimus Hempel, Aleurodicus mirabilis (Cockerell), Aleurodicus neglectus Quaintance and Baker, Bemisia tabaci (Gennadius), and Trialeurodes

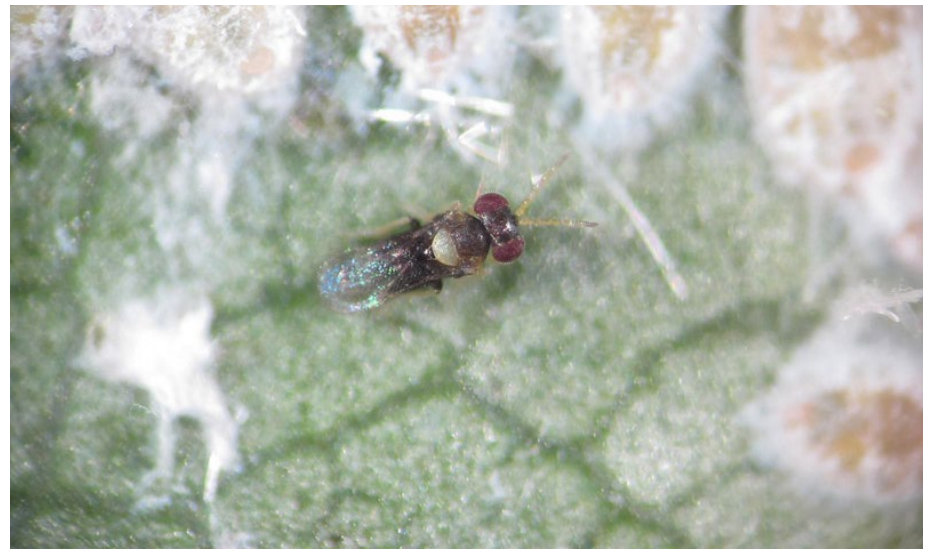

Figure 1. Dorsal view of Encarsia guadeloupae Credits: Siavash Taravati

vaporariorum (Westwood) (Evans 2008). Adult wasps can be identified by their yellow scutellum (a triangular plate on their back between the wings; the thorax area) against their brownish body (Fig. 1 and 2). Encarsia guadeloupae has been found on trees infested with rugose spiraling whitefly, parasitizing the whitefly nymphs. Under laboratory conditions, female wasps examine whitefly nymphs with their long antennae and probe with their ovipositor looking for a suitable site on the nymph to lay an egg. When a suitable site is found, the wasp will pierce the nymph with its ovipositor and lay an egg.

1. This document is ENY-870, one of a series of the Entomology and Nematology Department, UF/IFAS Extension. Original publication date August 2013. Visit the EDIS website at http://edis.ifas.ufl.edu.

2. Siavash Taravati, Ph.D candidate, Entomology and Nematology Department; Catharine Mannion, associate professor, Entomology and Nematology Department; Holly Glenn, senior biologist, Tropical Research and Education Center; and Lance Osborne, professor, IPM--biological control of insects and mites, Mid-Florida Research and Education Center, UF/IFAS Extension. 


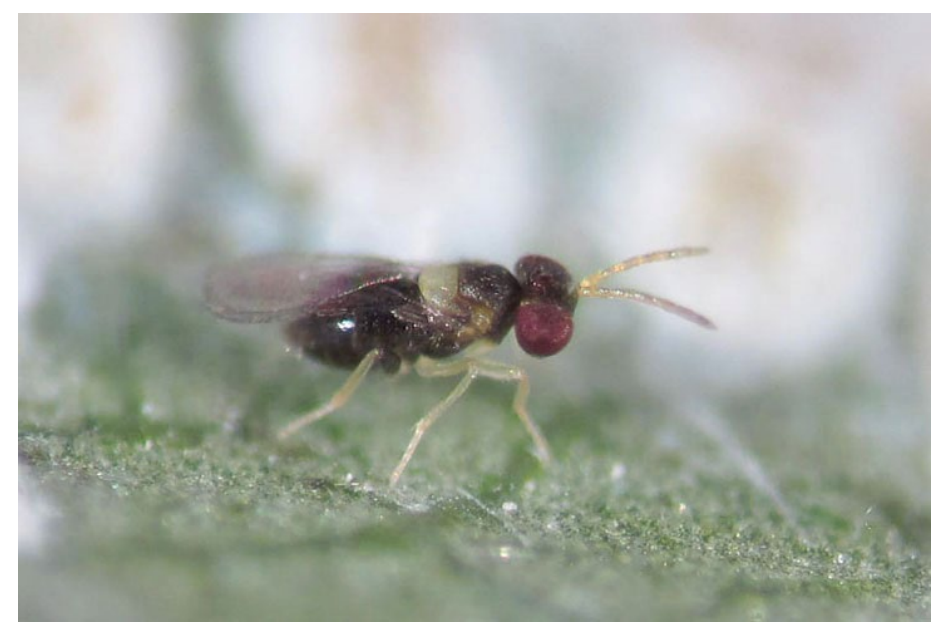

Figure 2. Lateral view of Encarsia guadeloupae. Credits: Siavash Taravati

\section{Encarsia noyesi Hayat (Hymenoptera: Aphelinidae)}

This wasp was originally imported from Mexico to California to control giant whitefly, Aleurodicus dugesii (Barton 1997). In 1998, it was imported from California to Florida to control the same whitefly species (Nguyen and Hamon). In 2012, this wasp was first collected from rugose spiraling whitefly infestations in Key Biscayne, FL, and continues to be collected from that site. Females of E. noyesi can be distinguished from E. guadeloupae by their light colored head (dark in E. guadeloupae) and iridescent bluish-white scutellum (yellow in E. guadeloupae) (Fig. 3 and 4). Adult males (Fig. 5) have a light colored head but have a dark scutellum.

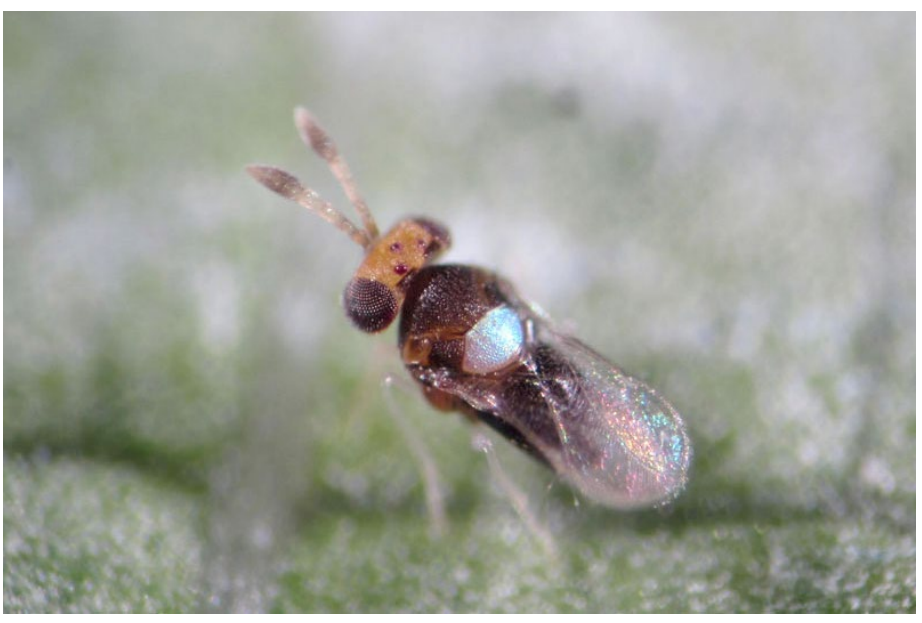

Figure 3. Female Encarsia noyesi. Credits: Siavash Taravati

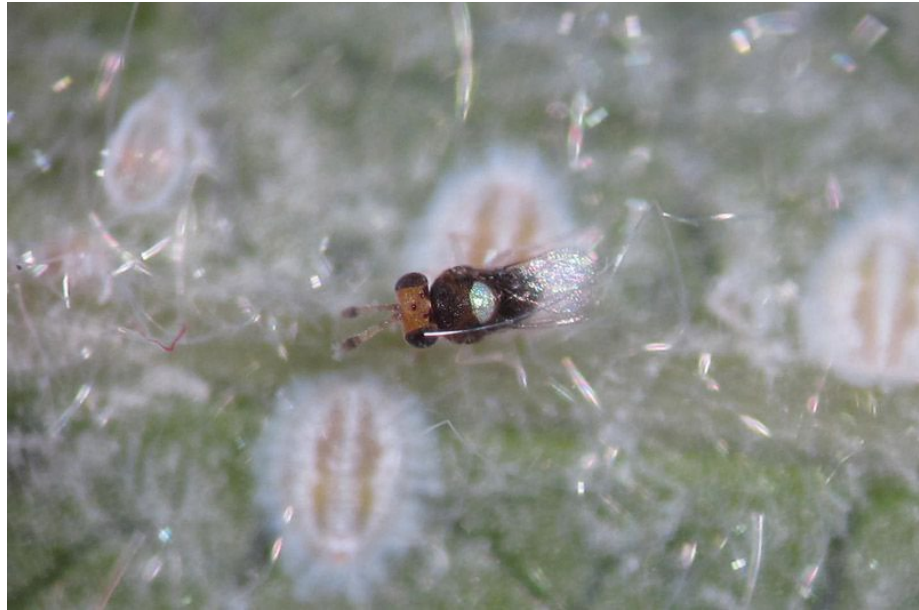

Figure 4. Female Encarsia noyesi walking among whitefly nymphs. Credits: Siavash Taravati

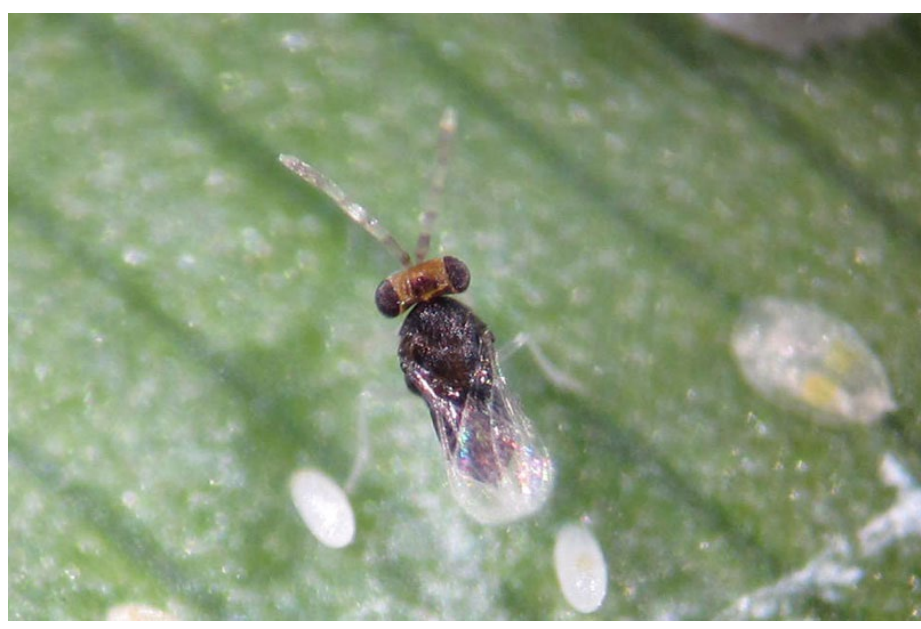

Figure 5. Male Encarsia noyesi. Credits: Siavash Taravati

\section{Aleuroctonus spp. (Hymenoptera: Eulophidae)}

Members of this genus have been reported only from whiteflies in the genus Aleurodicus. Aleuroctonus vittatus and an undescribed species of Aleuroctonus, which is near A. marki (G. Evans, personal communication), have been collected from rugose spiraling whitefly from the south Florida landscape. Aleuroctonus vittatus has been previously reported from Aleurodicus antillensis Dozier, Aleurodicus dispersus Russell, and Aleurodicus neglectus Quaintance and Baker. Aleuroctonus marki has been reported only from Aleurodicus dispersus Russell (Evans 2008).

Both species of Aleuroctonus are noticeably larger and more robust than E. guadeloupae and E. noyesi. They can be distinguished from the two aforementioned Encarsia species by their size and the pale color of the anterior part of the abdomen (Fig. 6). When an adult Aleuroctonus is 
standing still, its body is held at a slant with the head held much higher than the tip of the abdomen. Size, color, and stance make them easy to differentiate from E. guadeloupae and E. noyesi. Exit holes in whitefly nymphs from Aleuroctonus are usually larger than exit holes from the Encarsia species (Fig. 7).

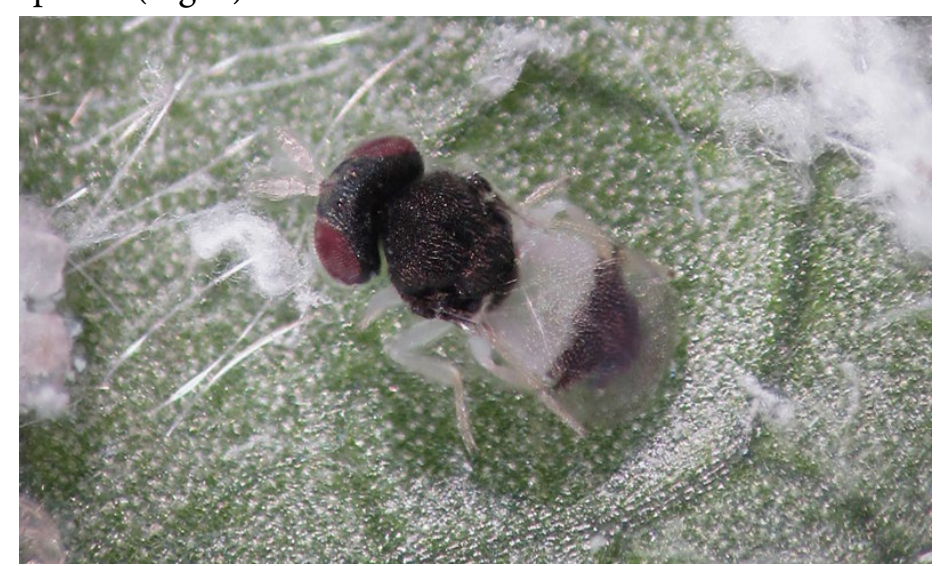

Figure 6. Aleuroctonus sp. Credits: Siavash Taravati

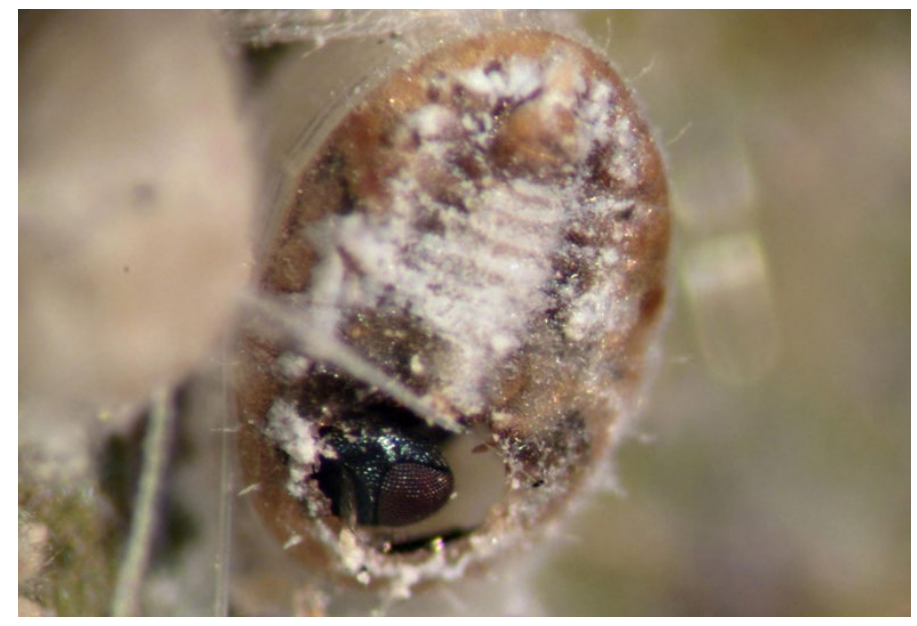

Figure 7. Aleuroctonus sp. emerging from a rugose spiraling whitefly pupa. Credits: Siavash Taravati

Under laboratory conditions, adult Aleuroctonus sp. are observed walking among or over whitefly nymphs. Once a suitable host is found, the wasp assesses the host using its antennae, which is seen as a vibration of the antenna. Soon after, the wasp rubs its front legs very quickly against the body of the host. This behavior often lasts a few minutes with one to few inactive periods in between. Most of these interactions, however, lead to the rejection of the host by the wasp. This is in contrast with the behavior of $E$. guadeloupae, which quickly starts probing into the host with its ovipositor. Only a few cases of Aleuroctonus host assessments lead to probing behavior (Fig. 8).

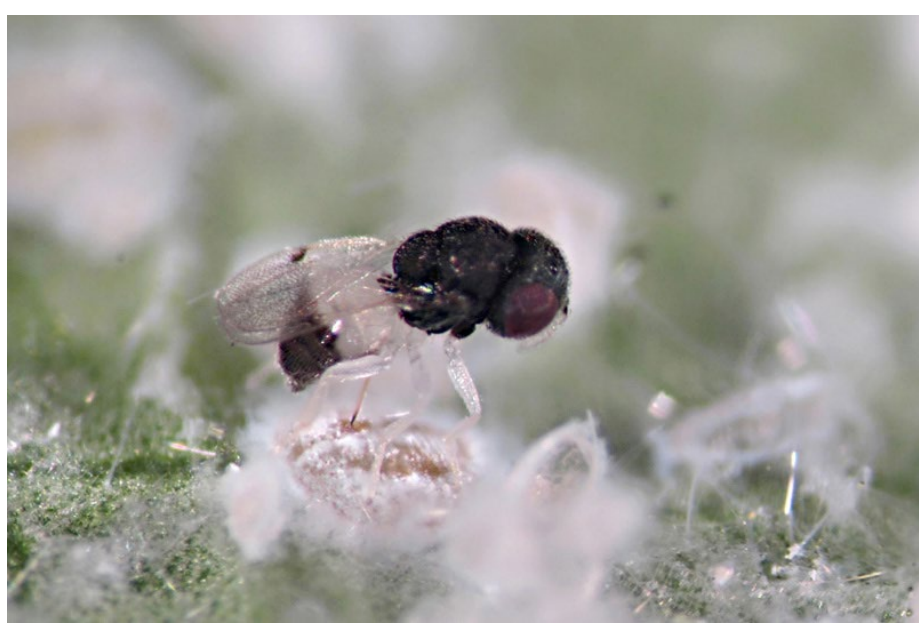

Figure 8. Aleuroctonus sp. probing into a rugose spiraling whitefly nymph. Credits: Siavash Taravati

\section{Nephaspis oculata (Blatchley, 1917) (Coleoptera: Coccinellidae)}

Nephaspis oculata has been reported as a predator of whiteflies from the United States. (Gordon 1985), the Bahamas (Turnbow and Thomas 2008) and Barbados (Peck 2009). It is distributed along the US Gulf Coast and has been reported from Florida, Louisiana, and Texas. It was first described as Scymnus oculata by Blatchley in 1917 from Dunedin, Florida. Later in 1952, Wingo described it as a new species, $N$. amnicola, from Boone, Iowa. The latter species is now considered as a synonym of N. oculata, and its reported occurrence in Iowa and New Hampshire is questionable (Gordon 1985; Gordon 1997).

This beetle has been widely studied for controlling silverleaf whitefly, B. tabaci, and was imported into Hawaii in 1979 for the control of spiraling whitefly, A. dispersus (Kumashiro et al. 1983). Larvae and adults feed on all life stages of $A$. dispersus, but nymphs are the dominant food. Both larvae and adults consume spiraling whitefly nymphs by piercing the integument and withdrawing the contents, which is followed by regurgitation of body contents and saliva (Yoshida and Mau 1985).

This predatory beetle has been observed on gumbo limbo trees infested with rugose spiraling whitefly in south Florida, where it feeds on the whitefly. Eggs are laid singly on the infested leaves. The eggs can be difficult to find because they are transparent, laid in relatively low numbers, and camouflaged by the waxy flocculent material produced by rugose spiraling whitefly.

The first instar of $N$. oculata is relatively clean of the waxy flocculent material from the whitefly, but the later instars cover themselves with it when feeding on rugose spiraling 
whitefly. Larval and pupal stages of the beetle are shown in Fig. 9 with the waxy flocculent material from the whitefly removed. Beetle larvae have been observed feeding on the first and second instar nymphs of rugose spiraling whitefly. Beetle larvae also were seen examining the older, $4^{\text {th }}$ instar nymphs by attaching their mouthparts to the whitefly's body (Fig. 10), but whether or not they were actually feeding is not clear.

Beetle pupae can be found easily on the lower surface of the leaves. They are whitish at first (Fig. 11) but become darker closer to adult emergence (Fig. 12). The approximate age of the pupae can be determined by the general color of the body and the pigmentation of eyes and elytra (Fig.13).

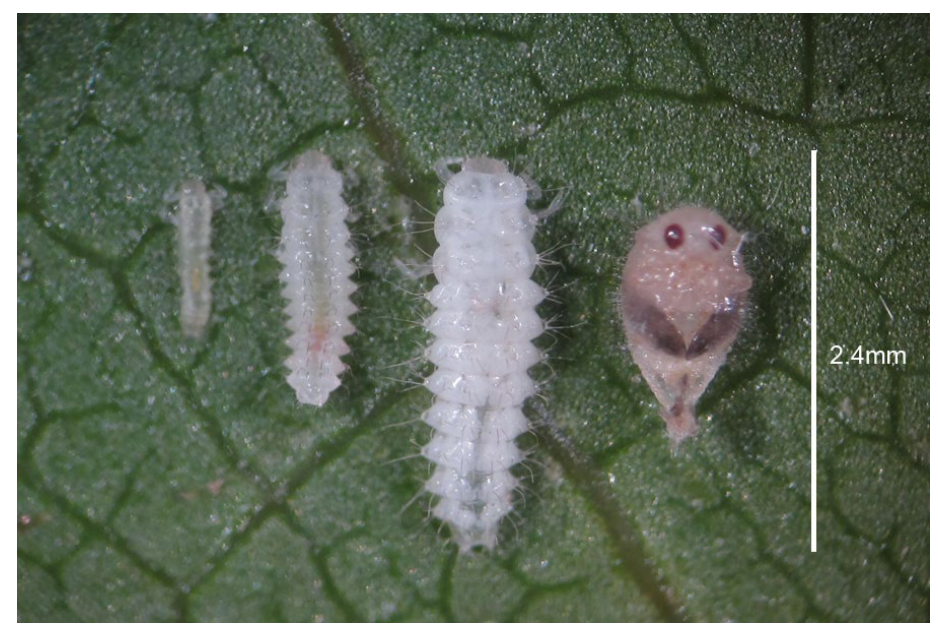

Figure 9. Nephaspis oculata. $2^{\text {nd }}, 3^{\text {rd }}, 4^{\text {th }}$ instars and pupa (waxy flocculent material from rugose spiraling whitefly removed). Credits: Siavash Taravati

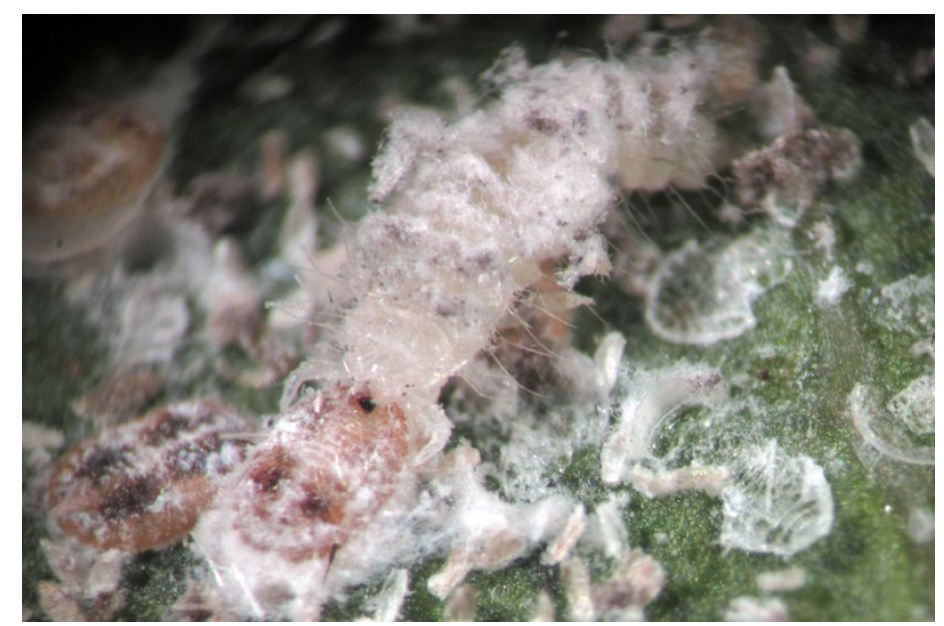

Figure 10. Nephaspis oculata larva attached to a fourth instar RSW nymph. Credits: Siavash Taravati

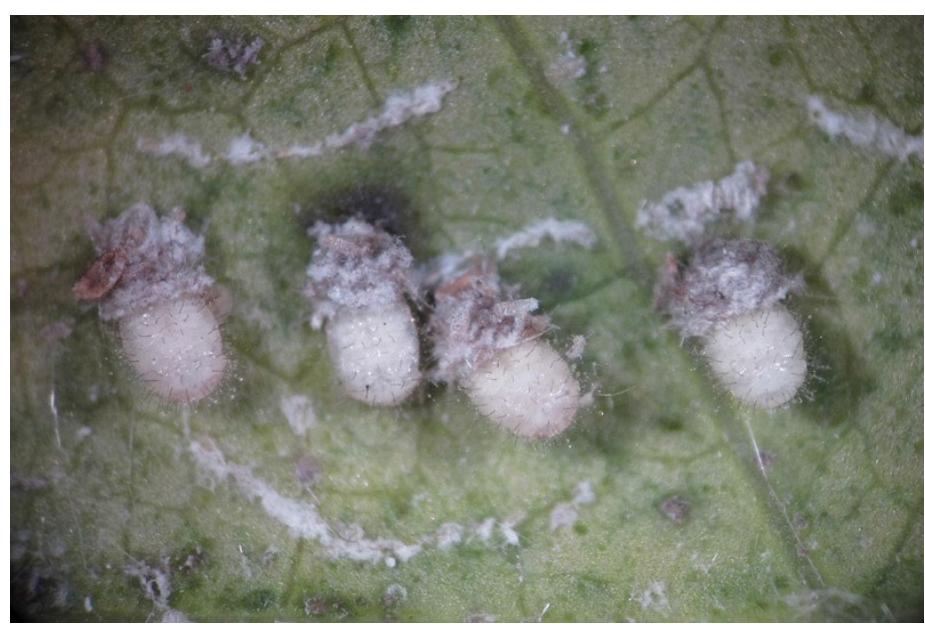

Figure 11. Nephaspis oculata pupae on gumbo limbo. Credits: Siavash Taravati

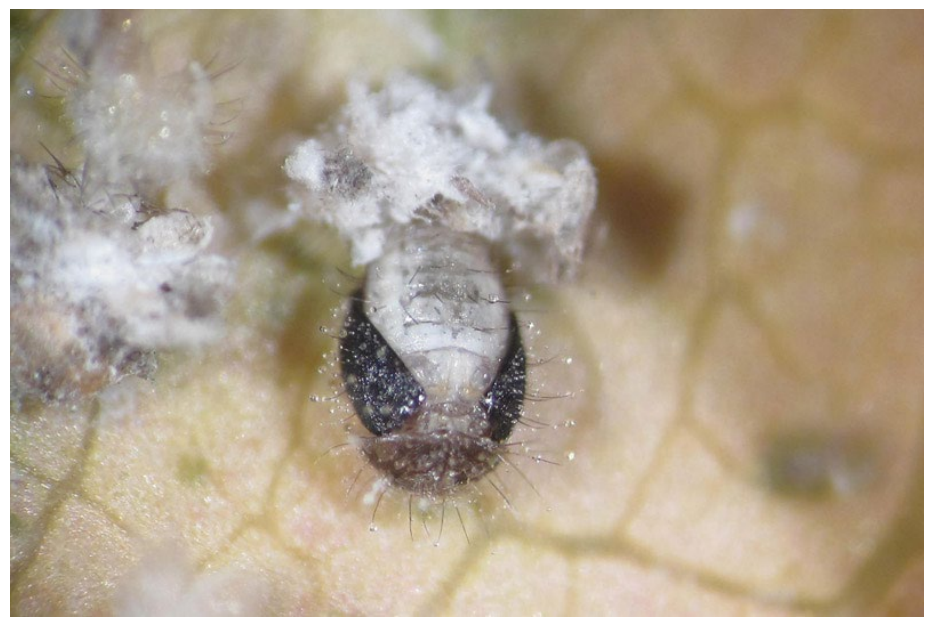

Figure 12. Nephaspis oculata pupa in its natural position close to adult emergence (dorsal view). Credits: Siavash Taravati

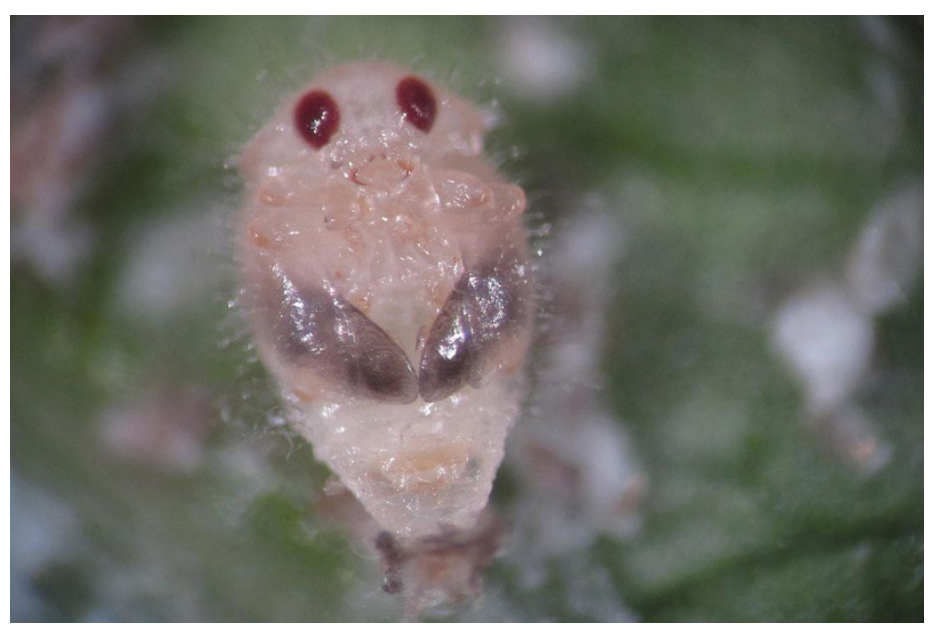

Figure 13. Ventral view of Nephaspis oculata pupa. Credits: Siavash Taravati 
Adult beetles are small $(1.2-1.5 \mathrm{~mm})$, brownish and pubescent. They can be sexed by the color of their pronotum, which is yellowish in males and dark brown in females (Fig. 14). The elytra and abdomen are dark brown in both sexes.
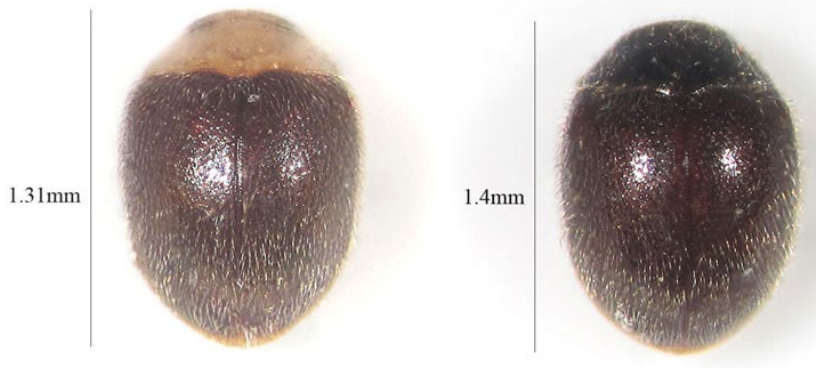

Figure 14. Adult Nephaspis oculata: male (left) and female (right). Credits: Siavash Taravati

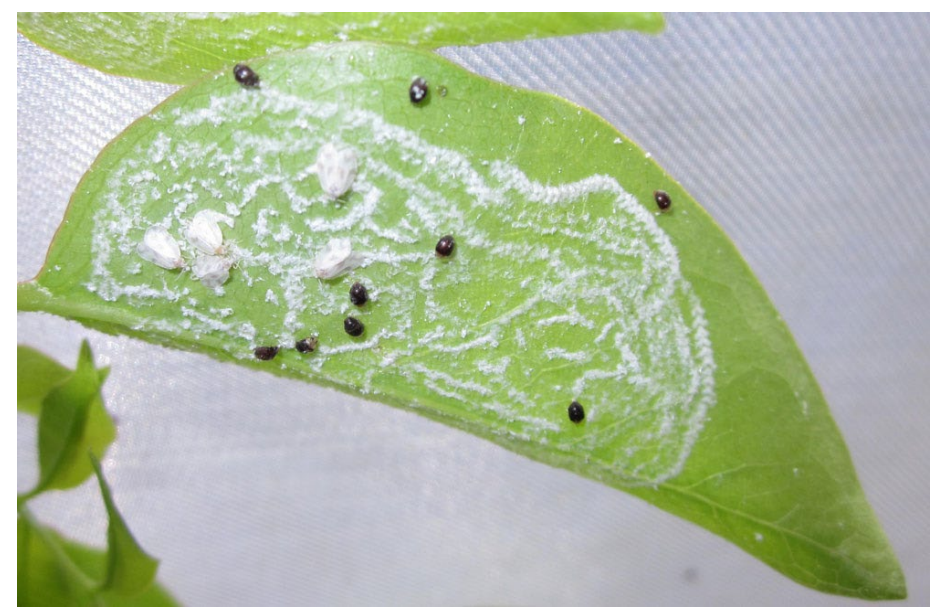

Figure 15. Adult Nephaspis oculata feeding on whitefly eggs. Credits: Siavash Taravati

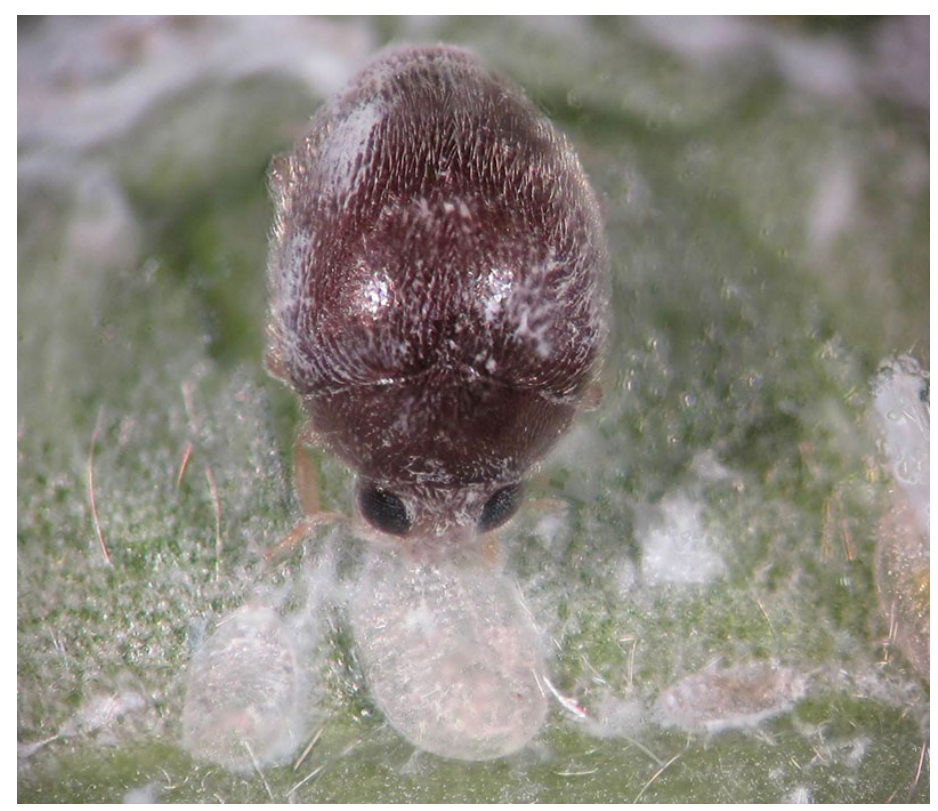

Figure 16. Female Nephaspis oculata feeding on a $4^{\text {th }}$ instar whitefly. The body contents of the nymph are almost completely withdrawn by the beetle. Credits: Siavash Taravati
Adult beetles have been observed feeding on eggs and all instars of rugose spiraling whitefly. In an outdoor caged colony, we observed adult beetles aggregating on leaves with freshly laid egg spirals whenever the whitefly nymphs become scarce (Fig. 15).

Similar to the observation by Yoshida and Mau (1985), we observed adult beetles piercing the integument of the nymphs and gradually pumping the body contents of the nymphs into their mouths combined with intermittent regurgitations of a translucent liquid (probably a mixture of saliva and whitefly body contents) back into the body of the nymphs. This behavior was seen on a freshly molted $4^{\text {th }}$ instar rugose spiraling whitefly nymph, which has a semi-transparent body (Fig. 16). During each withdrawalregurgitation cycle, we were able to clearly see the direction of fluid movement within the body of the nymph, which is marked by the occurrence of many bubbles during regurgitation.

\section{Lacewings (Neuroptera: Chrysopidae)}

Lacewing larvae have been collected from infested foliage in many locations in south Florida. Lacewings are generalist predators that feed on different groups of insects including aphids and whiteflies. The lacewing larvae that are associated with rugose spiraling whitefly are trash carriers that cover themselves with wax, eggs, cast skins, pupal cases and even carcasses of adult whiteflies.

Lacewing larvae collected from whitefly-infested trees in south Florida were reared to adults in the laboratory and determined to be Ceraeochrysa sp. These lacewings have been observed consuming rugose spiraling whitefly nymphs (Fig. 17). Adults (Fig. 18) are distinguished by their wing venation and the reddish pigments on the scape of the antennae.

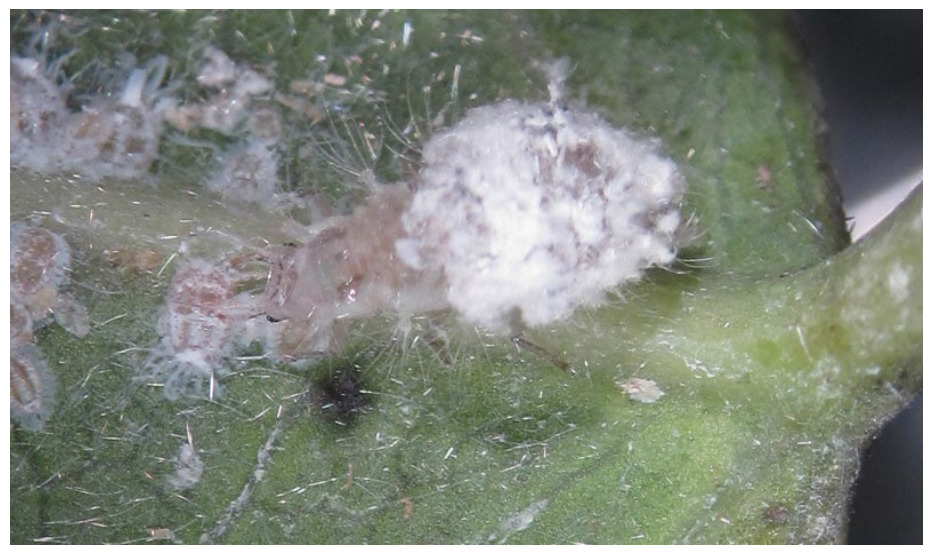

Figure 17. Lacewing larva feeding on the whitefly nymphs. Credits: Siavash Taravati 


\section{Management}

The natural enemies mentioned in this publication have been collected from different locations in Miami-Dade and appear to be naturally dispersing in areas of whitefly infestation. This suggests that they are able to locate rugose spiraling whitefly infestations and reproduce on them without any human aid. Nevertheless, their long-term efficacy in the field needs to be evaluated by entomologists.

\section{Acknowledgement}

We would like to thank Dr. Gregory A. Evans for the identification of parasitoid species and Dr. Michael C. Thomas (Florida Department of Agriculture and Consumer Services Division of Plant Industry) for the identification of beetle specimens we collected during the study.

\section{References}

Barton, K. 1997. Scientists pit natural enemies against giant whitefly. http://ucce.ucdavis.edu/files/repositoryfiles/ ca5106p5-67707.pdf. (Accessed: June 2012)

Evans, G. A. 2008. The whiteflies (Hemiptera: Aleyrodidae) of the world and their host plants and natural enemies. http://www.sel.barc.usda.gov:8080/1WF/World-WhiteflyCatalog.pdf. (Accessed: May 2012)

Gordon, R. D. 1985. The Coccinellidae (Coleoptera) of America, north of Mexico. Journal of the New York Entomological Society 93: 1-912.

Gordon, R. D. 1997. South American Coccinellidae (Coleoptera). Part 5: a taxonomic revision of the genus Nephaspis Casey. Frustula Entomologica 19: 1-50.

Kumashiro, B. R., P. Y. Lai, G. Y. Funasaki, and K. K. Teramoto. 1983. Efficacy of Nephaspis amnicola and Encarsia? haitiensis in controlling Aleurodicus dispersus in Hawaii. Proceedings of the Hawaiian Entomological Society 24: 261-269.

Martin, J. H. 2004. Whiteflies of Belize (Hemiptera: Aleyrodidae). Part 1-introduction and account of the subfamily Aleurodicinae Quaintance \& Baker. Zootaxa 681: $1-119$.

Nguyen, R., and A. B. Hamon. Biological control of giant whitefly, Aleurodicus dugesii Cockerell, in Florida. http:// www.freshfromflorida.com/pi/methods/giant-whitefly-bc. html. (Accessed: July 2012)

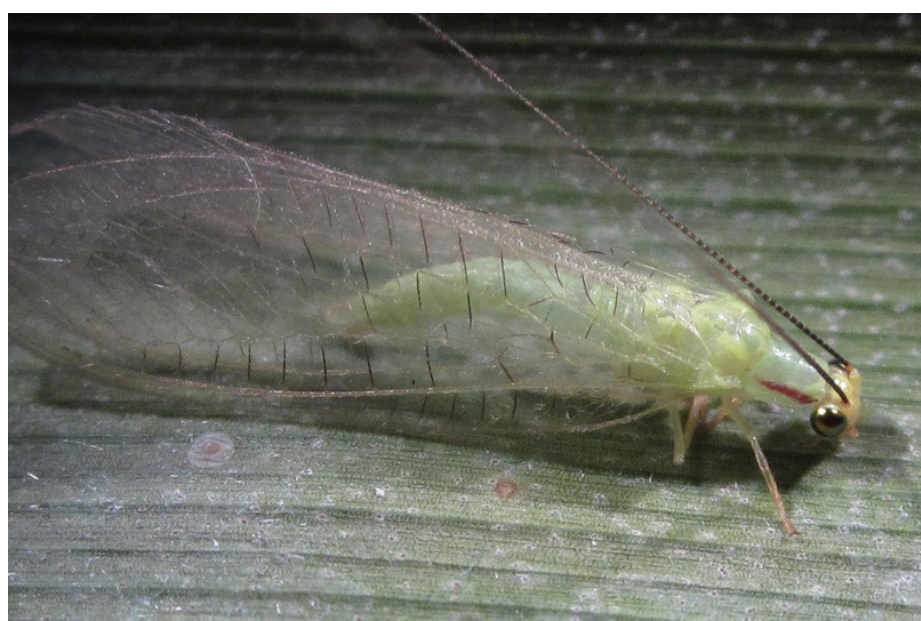

Figure 18. Adult Ceraeochrysa sp. Credits: Siavash Taravati

Peck, S. B. 2009. The beetles of Barbados, West Indies (Insecta: Coleoptera): diversity, distribution and faunal structure. Insecta Mundi 0073: 1-51.

Stocks, I. C., and G. Hodges. 2012. The rugose spiraling whitefly, Aleurodicus rugioperculatus Martin, a new exotic whitefly in South Florida (Hemiptera: Aleyrodidae). http:// www.freshfromflorida.com/pi/pest-alerts/pdf/aleurodicusrugioperculatus-pest-alert.pdf. (Accessed: June 2012)

Turnbow, R. H., Jr., and M. C. Thomas. 2008. An annotated checklist of the Coleoptera (Insecta) of the Bahamas. Insecta Mundi 0034: i, 1-64.

Yoshida, H. A., and R. F. L. Mau. 1985. Life history and feeding behaviour of Nephaspis amnicola Wingo. Proceedings of the Hawaiian Entomological Society 25: 155-160. 